Article

\title{
Fluorescent Property of Chitosan Oligomer and Its Application as a Metal Ion Sensor
}

\author{
Hun Min Lee ${ }^{1}$, Min Hee Kim ${ }^{1}$, Young Il Yoon ${ }^{2, *}$ and Won Ho Park ${ }^{1, *}$ \\ 1 Department of Advanced Organic Materials and Textile System Engineering, \\ Chungnam National University, Daejeon 34134, Korea; hun1062@naver.com (H.M.L.); \\ vvvkmhvvv@nate.com (M.H.K.) \\ 2 Laboratory of Molecular Imaging and Nanomedicine (LOMIN), National Institute of Biomedical \\ Imaging and Bioengineering (NIBIB), National Institutes of Health (NIH), Bethesda, MD 20892, USA \\ * Correspondence: youngil.yoon@nih.gov (Y.I.Y.); parkwh@cnu.ac.kr (W.H.P.); \\ Tel.: +1-301-827-0575 (Y.I.Y.); +82-42-821-6613 (W.H.P.)
}

Academic Editors: David Harding and Hitoshi Sashiwa

Received: 26 December 2016; Accepted: 29 March 2017; Published: 4 April 2017

\begin{abstract}
An aqueous solution was successfully prepared using a low-molecular-weight chitosan oligomer and FITC, and its structural and fluorescent properties were observed by using ${ }^{1} \mathrm{H} N M R$, ${ }^{13} \mathrm{C}$ NMR, FT-IR, XRD, UV-Vis, and PL spectrometry. Its application as a metal ion sensor was also evaluated. The fluorescence in the water-soluble chitosan oligomer was a result of the carbamato anion (NHCOO-), and a synthesized FITC-labeled chitosan oligomer exhibited an effective detection effect for copper ion as well as energy transfer by the ion near FITC that caused a fluorescence decrease (quenching). The chitosan oligomer was confirmed to be applicable as a selective and sensitive colorimetric sensor to detect $\mathrm{Cu}^{2+}$.
\end{abstract}

Keywords: chitosan oligomer; fluorescent property; metal ion sensor

\section{Introduction}

Among all natural polymers, chitosan is a promising biopolymer that is commercially available. It is a well-known polysaccharide that is mainly produced from chitin [1], and in the past few decades, naturally occurring chitosan has attracted a significant amount of interest due to its large quantities in nature, biodegradability, and extensive applicability [2]. A water-soluble chitosan oligomer is composed of $\beta$-(1,4)-2-amido-2-deoxy-D-glucan and $\beta$-(1,4)-2-acetoamido-2-deoxy-D-glucan (acetylglucosamine), and a substance with a low molecular weight can be obtained through acidic or enzymatic hydrolysis of chitosan. To date, many researchers have examined chitosan oligomers as promising materials for biomedical applications due to their good biocompatibility, biodegradability, antimicrobial activity, and wound healing effects [3-5].

Dye-labeled chitosan can be also employed in bio-imaging systems because it has little toxicity. Some dyes, such as Alexa Fluor, Cibacron Blue, and fluorescein isothiocyanate (FITC), have been used to create a dye-labeled chitosan particulate system [6]. However, a significant part of such approaches uses chemical reagents in the synthesis of dye-labeled chitosan due to its low solubility in water [7]. Numerous studies have addressed the utilization of chitosan as a fluorescence probe [8,9]. This approach has limited applicability in medical and pharmaceutical applications because most of these may be environmentally toxic or biologically hazardous [10].

Copper ions $\left(\mathrm{Cu}^{2+}\right)$ have been classified as a potentially carcinogenic substance because they induce DNA damages [11]. Malondialdehyde and 4-hydroxynonenal are produced through a reaction of the ions with lipid hydroxyperoxide, and this can result in impairment to tissues [12]. Therefore, effective detection of these ions is required for various fields [13]. 
This study focused on the fluorescent property of a low-molecular-weight chitosan oligomer and an environmentally friendly approach using a water-soluble chitosan derivative to sense the metal ion $\left(\mathrm{Cu}^{2+}\right)$. The simple synthesis and fluorescent properties of the FITC-labeled chitosan oligomer were carried out in distilled water.

\section{Materials and Methods}

\subsection{Materials}

A chitosan (CHI) oligomer was provided by Kittolife Co., Pyeongtaek, Korea. Its degree of deacetylation (DD), molecular weight, and $\mathrm{Cl}$ ion content were $97 \%, \sim 1000 \mathrm{Da}$, and $3.2 \%$ respectively. Fluorescein isothiocyanate (FITC) was purchased from Sigma-Aldrich Co., Saint Louis, MO, USA. Ethanol (EtOH) was obtained from Samchun Chemical Co., Yeosu, Korea. Metal cations such as $\mathrm{Na}^{+}$, $\mathrm{Cr}^{+}, \mathrm{Ni}^{+}, \mathrm{Sn}^{+}, \mathrm{Li}^{2+}, \mathrm{Mg}^{2+}, \mathrm{Al}^{2+}, \mathrm{Co}^{+}, \mathrm{Ni}^{2+}, \mathrm{Cu}^{2+}, \mathrm{Zn}^{2+}, \mathrm{Cd}^{2+}, \mathrm{Hg}^{2+}, \mathrm{Pb}^{2+}$, and $\mathrm{Fe}^{3+}$ were supplied from Alfa Aesar Co., Haverhill, MA, USA. The chemicals were used without further purification or additional processes.

\subsection{Preparation of CHI Oligomer-FITC Complexes}

To conduct the one-step synthesis of CHI oligomer-FITC complexes, $100 \mathrm{~mL}$ solutions of $0.01 \%-0.05 \%(w / v)$ FITC in EtOH were added to a $10 \mathrm{~mL}$ solution of $2 \%(w / v) \mathrm{CHI}$ oligomer in distilled water (DW). To obtain the desired products, the solutions were stirred at room temperature for $24 \mathrm{~h}$ in a darkroom. After the reaction, the unreacted FITC was removed through two centrifugal separations at $4000 \mathrm{rpm}$ for $10 \mathrm{~min}$ using EtOH. The end products were obtained as a powder by using a vacuum dryer (VO-10x, Jeio Tech Co., Seoul, Korea) at room temperature for $24 \mathrm{~h}$.

\subsection{Structural Analyses of the CHI Oligomer and CHI Oligomer-FITC Complexes}

To verify the presence of carbamato anion (NHCOO-) in the $\mathrm{CHI}$ oligomer, ${ }^{13} \mathrm{C}$ nuclear magnetic resonance $\left({ }^{13} \mathrm{C} N M R\right)$ spectra were recorded on a NMR spectrometer $(300 \mathrm{MHz}, \mathrm{FT}-\mathrm{NMR}$, Bruker, Billerica, MA, USA). The Fourier transform vacuum infrared (FT-IR) spectra of the CHI oligomer-FITC complexes were collected using a FT-IR spectrometer (VERTEX 80v, Bruker) with a frequency range of $675-4000 \mathrm{~cm}^{-1}$, and X-ray diffraction (XRD) patterns were obtained at room temperature with $2 \theta=5^{\circ}-80^{\circ}$ using an X-ray diffractometer (D8 DISCOVER, Bruker AXS, Billerica, MA, USA) to confirm structural changes in the complexes. Also, the degree of substitution (DS) of the complexes is ascertained by recording ${ }^{1} \mathrm{H}$ nuclear magnetic resonance (1H NMR) spectra on a NMR spectrometer (300 MHz, FT-NMR, Bruker). The DS (\%) values were expressed as $\left(\mathrm{I}_{\mathrm{AR}} / 9\right) /\left(\mathrm{I}_{\mathrm{H} 2-\mathrm{H} 6} / 6\right) \times 100$ [7]. $\mathrm{I}_{\mathrm{AR}}$ and $\mathrm{I}_{\mathrm{H} 2-\mathrm{H} 6}$ indicated peak areas of aromatic protons in FITC and $\mathrm{C} 2-\mathrm{C} 6$ protons in the chitosan backbone, respectively.

\subsection{Fluorescent Analyses of the CHI Oligomer and CHI Oligomer-FITC Complexes}

To analyze the UV-Vis absorbance and photoluminescence (PL) properties of the CHI oligomer, aqueous solutions $(0.1 \%-7 \%(w / v))$ of the $\mathrm{CHI}$ oligomer in DW were prepared after stirring at room temperature for $1 \mathrm{~h}$. The absorption spectra of the solutions were conducted on a UV-Vis spectrophotometer (UV-2450PC, Shimadzu Co., Kyoto, Japan) with a measurable range of 190-1100 nm and a resolution of $0.1 \mathrm{~nm}$. The photoluminescence spectra of the solution were collected using a luminescence spectrophotometer (Varian Cary Eclipse, Varian, Palo Alto, CA, USA) equipped with a xenon flash lamp excitation source. The absorption spectra were obtained at $25{ }^{\circ} \mathrm{C}$ and the emission spectra of CHI oligomer and CHI oligomer-FITC were obtained at $475 \mathrm{~nm}$ and $520 \mathrm{~nm}$, respectively, using an excitation wavelength at $395 \mathrm{~nm}$ with resolution of $1 \mathrm{~nm}$ and scan rate of $600 \mathrm{~nm} / \mathrm{min}$. Also, the changes in the fluorescent spectra of the $\mathrm{CHI}$ oligomer-FITC complexes with or without metal ions were measured using the same UV-Vis and luminescence spectrophotometers. 


\subsection{Adsorption Behaviors of Metal Ions onto the CHI Oligomer-FITC Complex}

To examine applicability of the $\mathrm{CHI}$ oligomer-FITC complex as a colorimetric sensor, the reactions between the complex and the metal ions such as $\mathrm{Na}^{+}, \mathrm{Cr}^{+}, \mathrm{Ni}^{+}, \mathrm{Sn}^{+}, \mathrm{Li}^{2+}, \mathrm{Mg}^{2+}, \mathrm{Al}^{2+}, \mathrm{Co}^{+}, \mathrm{Ni}^{2+}$, $\mathrm{Cu}^{2+}, \mathrm{Zn}^{2+}, \mathrm{Cd}^{2+}, \mathrm{Hg}^{2+}, \mathrm{Pb}^{2+}$, and $\mathrm{Fe}^{3+}$ were monitored. The solutions containing metal ions $\left(10^{-3} \mathrm{M}\right.$, $0.1 \mathrm{~mL}$ ) were added into the $\mathrm{CHI}$ oligomer-FITC complex solutions $(1 \mathrm{~mL})$. After that, the changes in color of the mixed solutions were checked after exposure to UV radiation (Ex. $=395 \mathrm{~nm}$ ).

\section{Results and Discussion}

\subsection{Structural and Fluorescent Analyses of the CHI Oligomer}

The low-molecular-weight $\mathrm{CHI}$ oligomer with a high water solubility showed unique structural and fluorescent characteristics. In general, fluorescence is caused by molecules with delocalized electrons at conjugated double bonds [14]. The CHI oligomer featured a molecular structure that had no delocalized electron, but the fluorescent property of the oligomer was observed by the fluorescence photometer and the naked eye. Recently, several polymers without conjugated double bonds were reported to exhibit fluorescence [15], and it turned out that the carbamato anion (NHCOO-) formed by the reaction between carbon dioxide and amine induced this phenomenon [16]. The ${ }^{13} \mathrm{C}$ NMR spectrum in Figure 1A shows a typical carbamato anion (NHCOO-) peak in $\mathrm{CHI}$ oligomer at $174 \mathrm{ppm}$. It was induced by the reaction between the amino group in the $\mathrm{CHI}$ oligomer and carbon dioxide in air. The fluorescent intensity was monitored depending on the concentration of the $\mathrm{CHI}$ oligomer (Figure 1B,C). The excitation and emission wavelengths of the $\mathrm{CHI}$ oligomer were 400 and $470 \mathrm{~nm}$, respectively.

(A)
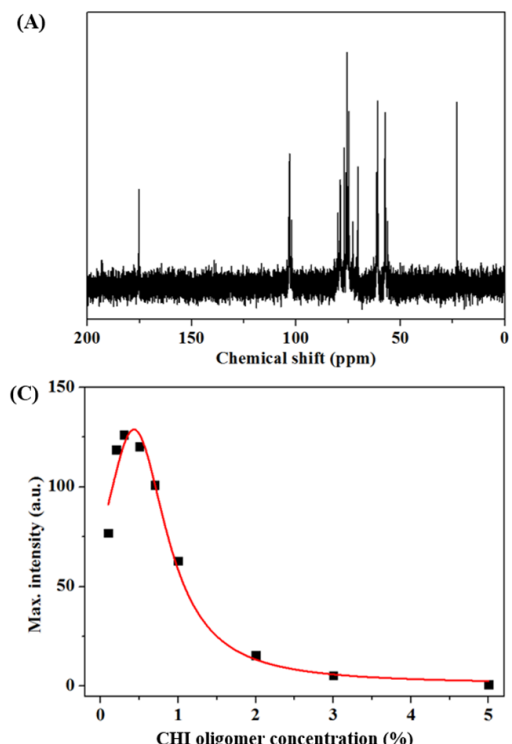

(E)

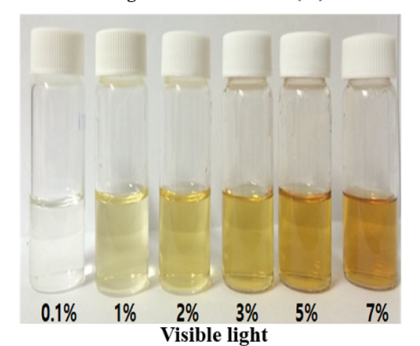

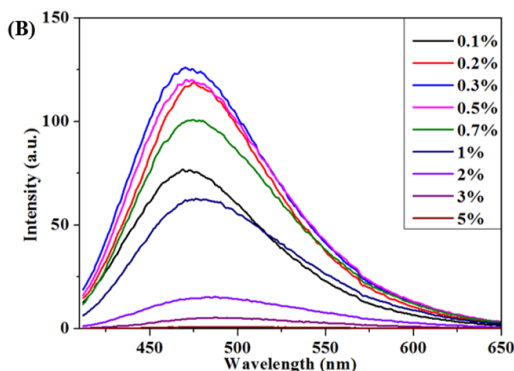

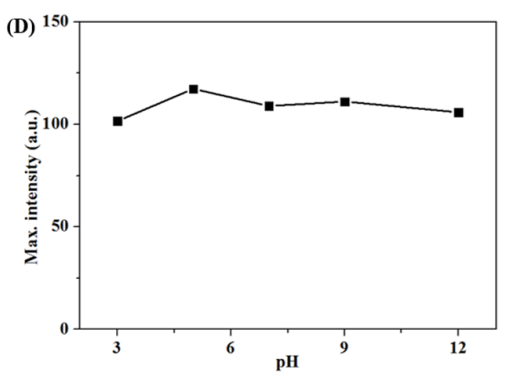

(F)

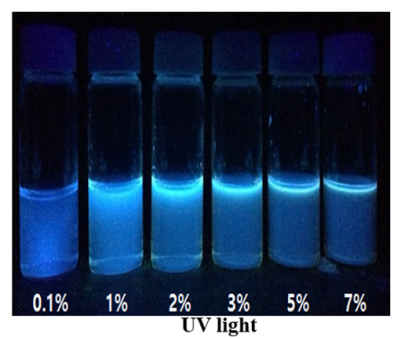

Figure 1. Analysis results of a CHI oligomer. ${ }^{13} \mathrm{C}$ NMR spectra (A); PL spectra (B), change in fluorescent intensities at $470 \mathrm{~nm}$ by the concentration of the $\mathrm{CHI}$ oligomer (C); change in fluorescent intensities at $470 \mathrm{~nm}$ by $\mathrm{pH}$ conditions (D); images under visible (E) or ultraviolet light (Ex. $=395 \mathrm{~nm})(\mathbf{F})$. 
The photoluminescence (PL) spectra revealed that the maximal CHI oligomer concentration showing the highest PL intensity was $0.3 \%(w / v)$. At $0.5 \%(w / v)$ and over, the PL intensities showed a tendency to decrease due to self-quenching among the $\mathrm{CHI}$ oligomer molecules [17]. The fluorescent pattern of the $\mathrm{CHI}$ oligomer was confirmed to be similar to that given in the results above under UV radiation (Ex. $=395 \mathrm{~nm}$ ) (Figure 1E,F). In addition, observation at various $\mathrm{pH}$ values from 3 to 12 revealed that the $\mathrm{PL}$ intensities of the $\mathrm{CHI}$ oligomer were unaffected by the $\mathrm{pH} 3-12$ conditions (Figure 1D).

\subsection{Structural and Fluorescent Analyses of the CHI Oligomer-FITC Complexes}

A reaction of a primary amine with an isothiocyanate (NCS), one of various amine modification methods, has been widely known to lead to a thiourea as its product [18]. Herein, to develop a sensitive and selective imaging probe that not only has high water solubility but is also immune to the $\mathrm{pH}$ conditions, the $\mathrm{CHI}$ oligomer-FITC complexes were prepared through a reaction of the $\mathrm{CHI}$ oligomer with FITC. The so-called "FITC labeling" reaction took place with the primary amine of the CHI oligomer and the NCS of FITC. The reaction mechanism is illustrated in Figure 2.

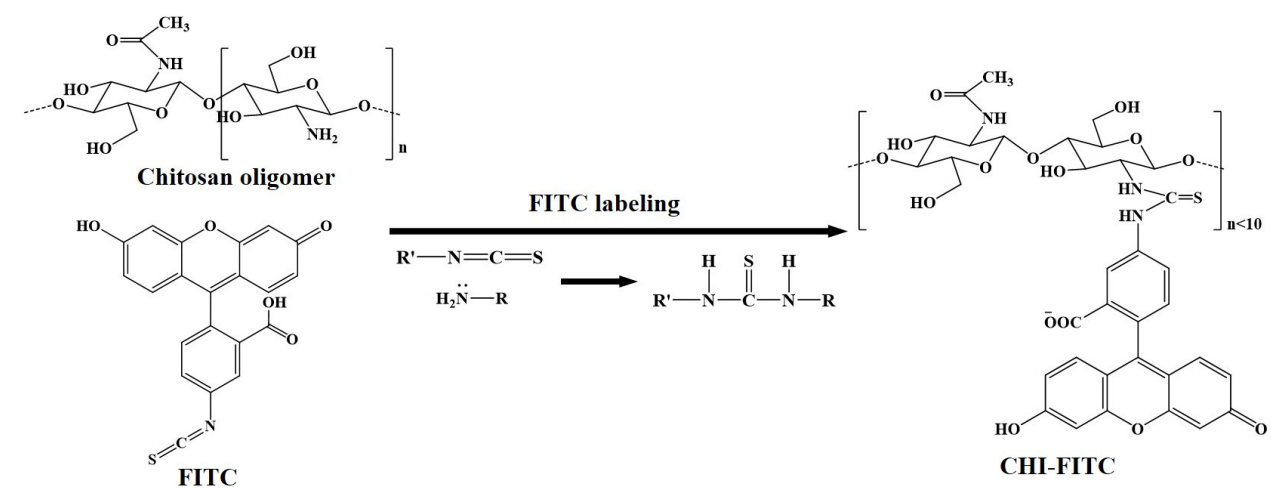

Figure 2. Schematic representation of a reaction mechanism between the CHI oligomer and FITC.

The optimal condition of this reaction was confirmed by obtaining the ${ }^{1} \mathrm{H}$ NMR, XRD, and FI-IR spectra [19-21]. The concentration of the CHI oligomer was fixed, and the concentration of FITC varied from 0 to $7 \times 10^{-2} \%(w / v)$. The peaks at $6.5-8 \mathrm{ppm}$, indicating aromatic rings, were observed with an increase in the FITC concentration (Figure 3A). Also, the DS (\%) was calculated by the proportion of areas of 6.5 to eight peaks corresponding to the nine protons of FITC to areas of three to four peaks corresponding to the six protons of the $\mathrm{CHI}$ oligomer (Figure 3B). The DS (\%) values increased to four depending on the FITC concentration. Therefore, the sample with DS $(\%)=4$ was named as CHI-FITC-4. In the same way, the samples with DS $(\%)=2$ or DS $(\%)=3$ were named as CHI-FITC-2 or CHI-FITC-3, respectively. Figure $3 \mathrm{C}$ shows the XRD patterns for the CHI-FITC complexes. A spectrum of the $\mathrm{CHI}$ oligomer showed $2 \theta=20^{\circ}$ as a typical crystalline peak. However, according to the increase in the DS (\%) value, the crystalline peak gradually decreased due to the introduction of a bulky FITC group. Due to the substitution of the amino group to thiourea by FITC, the steric hindrance between the $\mathrm{CHI}$ oligomers increased considerably, and hydrogen bonds were broken between the CHI oligomers. Also, through an FT-IR analysis, the peaks at 1458, 1535, and $1594 \mathrm{~cm}^{-1}$ related to the stretching vibration of the aromatic ring were clearly observed in the CHI-FITC-4 (Figure 3D). After the reaction of the CHI oligomer with FITC, a peak at $2015 \mathrm{~cm}^{-1}$ corresponding to the NCS vibration disappeared completely. Figure 3 verifies that the $\mathrm{CHI}$ oligomer-FITC complex was successfully synthesized. In addition, the fluorescent intensities of CHI-FITC-4 were evaluated from the PL spectra (Figure 4A,B), and the intensities were dependent on the concentration of CHI-FITC-4. 

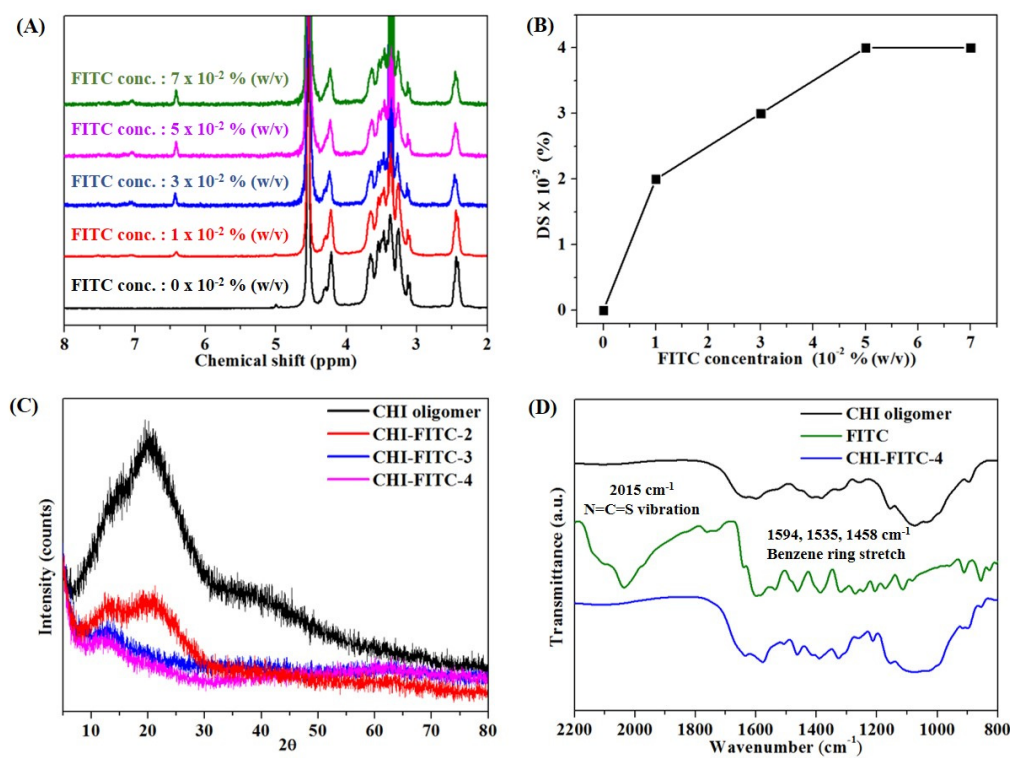

Figure 3. Results of the analysis of CHI-FITC complexes. ${ }^{1} \mathrm{H}$ NMR spectra (A); DS (B); XRD spectra (C); FT-IR spectra (D).
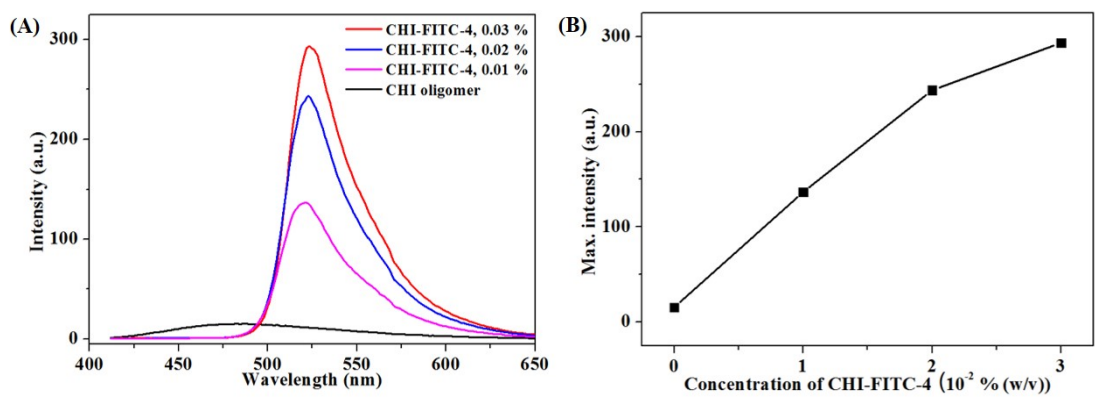

Figure 4. Results of the analysis of CHI-FITC-4 depending on the concentration. PL spectra (A); PL intensity at $520 \mathrm{~nm}($ B).

\subsection{Colorimetric Sensing of CHI-FITC-4 against Metal Ions}

Selectivity and sensitivity tests were carried out to assess the applicability of CHI-FITC-4 as a colorimetric sensor for metal ions. To begin, the selectivity of CHI-FITC-4 was investigated using metal ions such as $\mathrm{Na}^{+}, \mathrm{Cr}^{+}, \mathrm{Ni}^{+}, \mathrm{Sn}^{+}, \mathrm{Li}^{2+}, \mathrm{Mg}^{2+}, \mathrm{Al}^{2+}, \mathrm{Co}^{+}, \mathrm{Ni}^{2+}, \mathrm{Cu}^{2+}, \mathrm{Zn}^{2+}, \mathrm{Cd}^{2+}, \mathrm{Hg}^{2+}, \mathrm{Pb}^{2+}$, and $\mathrm{Fe}^{3+}$. Figure 5A,B show that the CHI-FITC-4 sample had selectivity for $\mathrm{Cu}^{2+}$. In particular, a decrease in the fluorescent intensity could be clearly distinguished from those of other metal ions under UV radiation (Ex. $=395 \mathrm{~nm}$ ). As quantitative criteria, the UV-vis and PL spectra of CHI-FITC-4 with metal ions were monitored (Figure 5C-F). The absorbance $\left(\lambda_{\max }=492 \mathrm{~nm}\right)$ and fluorescent intensity $\left(\lambda_{\max }=520 \mathrm{~nm}\right)$ of CHI-FITC-4 with $\mathrm{Cu}^{2+}$ decreased to approximately $60 \%$ and $80 \%$, respectively. According to the concentration range of $0.1-7.0 \mathrm{mM}$ for $\mathrm{Cu}^{2+}$, a sensitive colorimetric assay of CHI-FITC-4 was implemented, and the color changes were observed under UV radiation $(\mathrm{Ex}=395 \mathrm{~nm})$ (Figure 6A,B). The UV-vis spectra indicated that the limit of detection (LOD) of CHI-FITC-4 for $\mathrm{Cu}^{2+}$ was close to $60 \mu \mathrm{M}$, and its correlation coefficient $\left(R^{2}\right)$ was 0.99 (Figure 6C,D). In addition, the fluorescent intensities at $520 \mathrm{~nm}$ of CHI-FITC-4 with $\mathrm{Cu}^{2+}$ displayed a tendency for decay according to the concentration $\left(0.1-7.0 \mathrm{mM}\right.$ ) of $\mathrm{Cu}^{2+}$ (Figure $6 \mathrm{E}, \mathrm{F}$ ). This phenomenon could be explained by the fluorescent quenching mechanism. The fluorescence intensity of CHI-FITC-4 decreased due to energy transfer resulting from the formation of a selective complex with $\mathrm{Cu}^{2+}$, as shown in Figure 7. The energy transfer occurred due to $\mathrm{Cu}^{2+}$ being located near the FITC group, resulting in a decrease in fluorescence (quenching) [22]. 
(A)

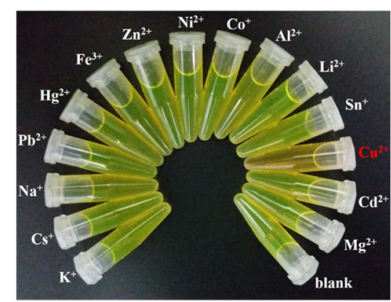

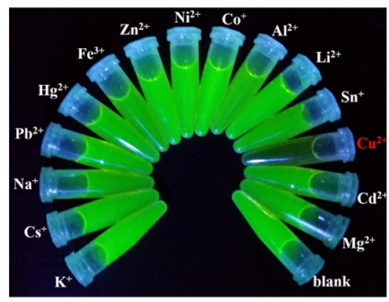
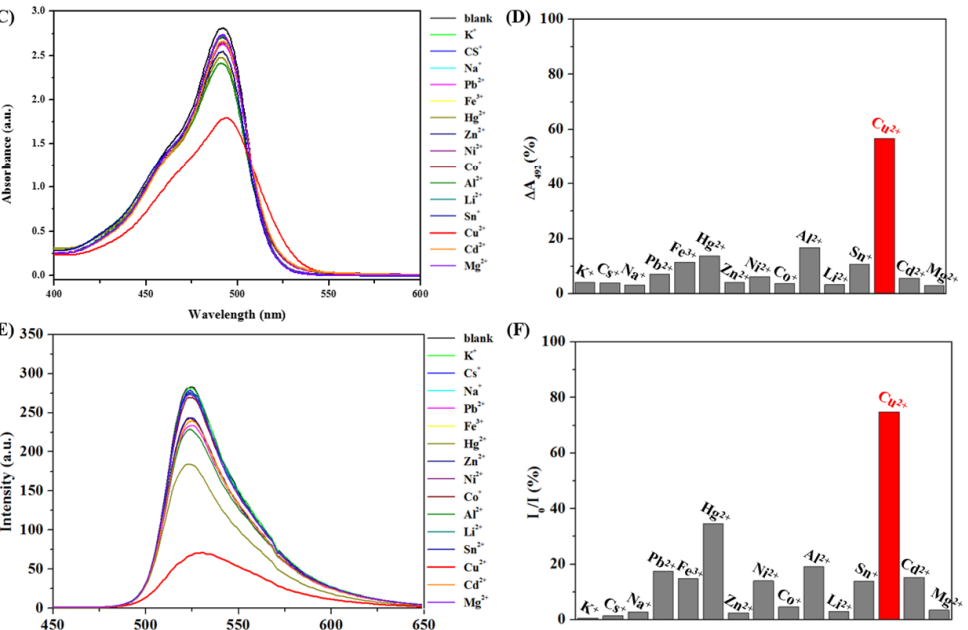

Figure 5. Colorimetric assay to sense metal ions using CHI-FITC-4. Images under visible (A) or ultraviolet radiation (B); UV-vis spectra (C); Change comparison of UV-vis intensity at $492 \mathrm{~nm}$ (D); PL spectra (E); Change comparison of PL intensity at $520 \mathrm{~nm}(\mathbf{F})$.

(A)

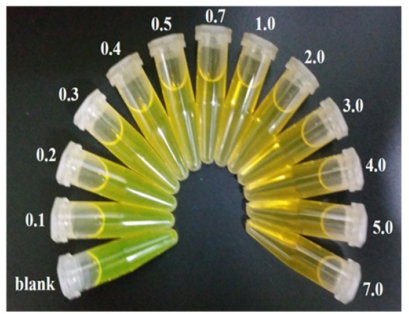

(C)
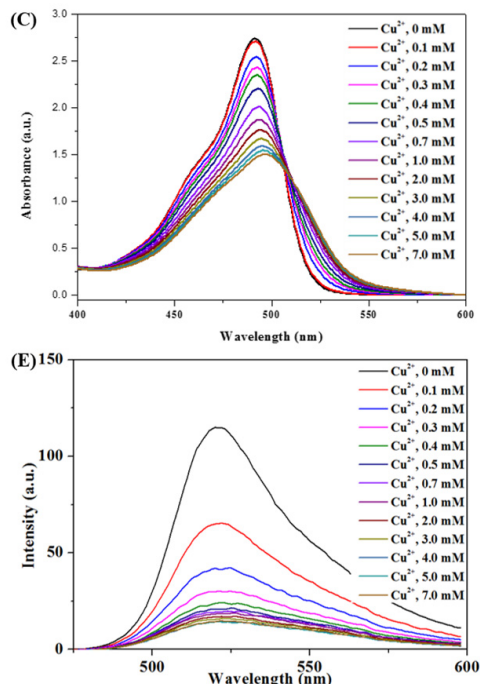

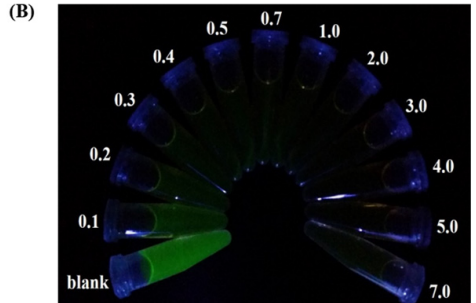

(D) $1.00-1 \mathrm{R}^{2}=0.99$
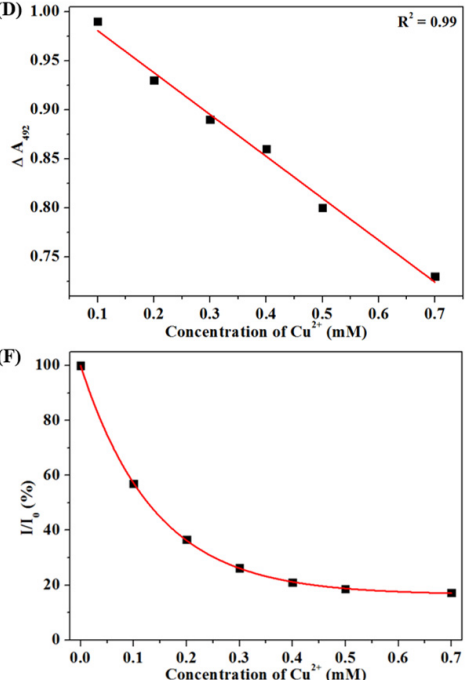

Figure 6. Colorimetric assay to sense $\mathrm{Cu}^{2+}$ using CHI-FITC-4. Images under visible (A) or ultraviolet radiation (B); UV-vis spectra (C); Change comparison of UV-vis intensity at $492 \mathrm{~nm}$ (D); PL spectra (E); Change comparison of PL intensity at $520 \mathrm{~nm}(\mathbf{F})$. 


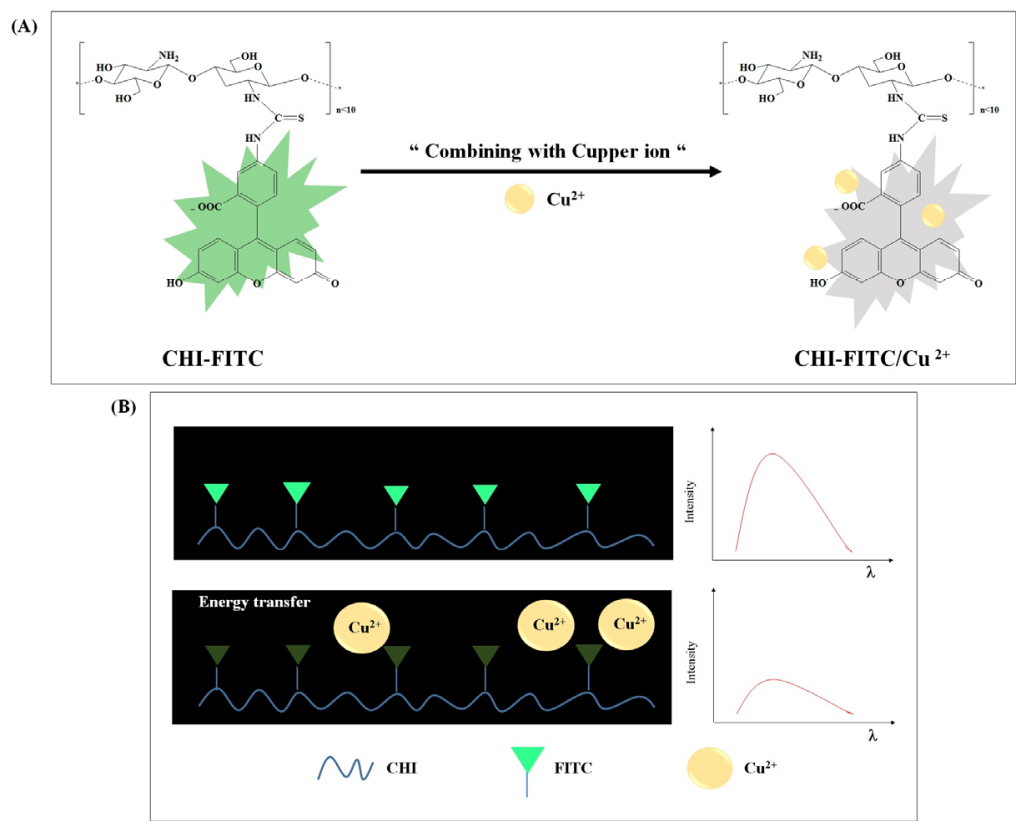

Figure 7. Schematic representation of the reaction mechanism between CHI-FITC and $\mathrm{Cu}^{2+}(\mathbf{A})$ and the energy transfer phenomenon (B).

\section{Conclusions}

In this study, aqueous solutions of low-molecular-weight $\mathrm{CHI}$ oligomers were successfully prepared, and their structural and fluorescent properties were then meticulously observed using ${ }^{1} \mathrm{H}$ NMR, ${ }^{13} \mathrm{C}$ NMR, FT-IR, XRD, UV-Vis, and PL spectrometry. The presence of the carbamato anion (NHCOO-) as a fluorophore was verified as the origin of the fluorescent properties of the CHI oligomer. With respect to the concentration and $\mathrm{pH}$ of the aqueous solutions of the $\mathrm{CHI}$ oligomer, the optimal concentration of the oligomer was $0.3 \%(w / v)$, and the solutions were not affected in the range of $\mathrm{pH}$ of 3-12. Depending on the addition of the metal ions, the color changes of the synthesized CHI oligomer-FITC complex showed a remarkable difference. It had an excellent selectivity to detect copper ions $\left(\mathrm{Cu}^{2+}\right)$, and its limit of detection (LOD) was $60 \mu \mathrm{M}$. When $\mathrm{Cu}^{2+}$ was combined with FITC, the energy transfer between FITC and $\mathrm{Cu}^{2+}$ led to fluorescent quenching of the CHI oligomer-FITC complex. In conclusion, the $\mathrm{CHI}$ oligomer-FITC complex has great potential as a promising colorimetric sensor to detect $\mathrm{Cu}^{2+}$.

Acknowledgments: This research was supported by the Basic Science Research Program through the National Research Foundation of Korea (NRF) funded by the Ministry of Science, ICT \& Future Planning (2015R1A2A2A01007954).

Author Contributions: Won Ho Park and Young Il Yoon conceived and designed the experiments; Hun Min Lee performed the experiments; Min Hee Kim and Hun Min Lee analyzed the data; Young Il Yoon and Won Ho Park wrote the paper.

Conflicts of Interest: The authors declare no conflict of interest.

\section{References}

1. Rinaudo, M. Chitin and chitosan: Properties and applications. Prog. Polym. Sci. 2006, 31, 603-632. [CrossRef]

2. Ilium, L. Chitosan and its use as a pharmaceutical excipient. Pharm. Res. 1998, 15, 1326-1331. [CrossRef]

3. Agrawal, P.; Strijkers, G.J.; Nicolay, K. Chitosan-based systems for molecular imaging. Adv. Drug Deliv. Rev. 2010, 62, 42-58. [CrossRef] [PubMed]

4. Kumar, M.R. A review of chitin and chitosan applications. React. Funct. Polym. 2000, 46, 1-27. [CrossRef]

5. Pan, X.; Ren, W.; Gu, L.; Wang, G.; Liu, Y. Photoluminescence from chitosan for bio-imaging. Aust. J. Chem. 2014, 67, 1422-1426. [CrossRef] 
6. Cormode, D.P.; Skajaa, T.; Fayad, Z.A.; Mulder, J.M. Nanotechnology in medical imaging probe design and applications. Arterioscler. Thromb. Vasc. Biol. 2009, 29, 992-1000. [CrossRef] [PubMed]

7. Gonil, P.; Sajomsang, W.; Ruktanonchai, U.R.; Ubol, P.N.; Treetong, A.; Opanasopit, P.; Puttipipatkhachorn, S. Synthesis and fluorescence properties of $N$-substituted 1-cyanobenz[f]isoindole chitosan polymers and nanoparticles for live cell Imaging. Biomacromolecules 2014, 15, 2879-2888. [CrossRef] [PubMed]

8. Huang, H.; Liu, F.; Chen, S.; Zhao, Q.; Liao, B.; Long, Y.; Zeng, Y.; Xia, X. Enhanced fluorescence of chitosan based on size change of micelles and application to directly selective detecting $\mathrm{Fe}^{3+}$ in humanserum. Biosens. Bioelectron. 2013, 42, 539-544. [CrossRef] [PubMed]

9. Qaqish, R.; Amiji, M. Synthesis of a fluorescent chitosan derivative and its application for the study of chitosan-mucin interactions. Carbohydr. Polym. 1999, 38, 99-107. [CrossRef]

10. Keana, T.; Thanou, M. Biodegradation, biodistribution and toxicity of chitosan. Adv. Drug Deliv. Rev. 2010, 62, 3-11. [CrossRef] [PubMed]

11. Aruoma, O.I.; Halliwell, B.; Gajewski, E.; Dizdaroglu, M. Copper-ion-dependent damage to the bases in DNA in the presence of hydrogen peroxide. Biochem. J. 1991, 273, 601-604. [CrossRef] [PubMed]

12. Kobal, A.B.; Horvat, M.; Prezelj, M.; Briski, A.S.; Krsnik, M.; Dizdarevic, T.; Mazej, D.; Falnoga, I.; Stibilj, V.; Arneric, N.; et al. The impact of long-term past exposure to elemental mercury on antioxidative capacity and lipid peroxidation in mercury miners. J. Trace Elem. Med. Biol. 2004, 17, 261-274. [CrossRef]

13. Gumpu, M.B.; Sethuraman, S.; Krishnan, U.M.; Rayappan, J.B.B. A review on detection of heavy metal ions in water-an electrochemical approach. Sens. Actuators B Chem. 2015, 213, 515-533. [CrossRef]

14. Jameson, D.M.; Croney, J.C.; Moens, P.D. Fluorescence: Basic concepts, practical aspects, and some anecdotes. Methods Enzymol. 2003, 360, 1-43. [PubMed]

15. Pan, X.; Wang, G.; Lay, C.L.; Tan, B.H.; He, C.; Liu, Y. Photoluminescence from amino-containing polymer in the presence of $\mathrm{CO}_{2}$ : Carbamato anion formed as a fluorophore. Sci. Rep. 2013, 3, 1-6. [CrossRef] [PubMed]

16. Zhang, X.; Lee, S.; Liu, Y.; Lee, M.; Yin, J.; Sessler, J.L.; Yoon, J. Anion-activated, thermoreversible gelation system for the capture, release, and visual monitoring of $\mathrm{CO}_{2}$. Sci. Rep. 2014, 4, 1-8. [CrossRef] [PubMed]

17. Dulkeith, E.; Morteani, A.C.; Niedereichholz, T.; Klar, T.A.; Feldmann, J. Fluorescence quenching of dye molecules near gold nanoparticles: Radiative and nonradiative effects. Phys. Rev. Lett. 2002, 89, 1-4. [CrossRef] [PubMed]

18. Serdyuk, O.V.; Heckel, C.M.; Tsogoeva, S.B. Bifunctional primary amine-thioureas in asymmetric organocatalysis. Org. Biomol. Chem. 2013, 11, 7051-7071. [CrossRef] [PubMed]

19. Lavertu, M.; Xia, Z.; Serreqi, A.N.; Berrada, M.; Rodrigues, A.; Wang, D.; Buschmann, M.D.; Gupta, A. A validated $1 \mathrm{H}$ NMR method for the determination of the degree of deacetylation of chitosan. J. Pharm. Biomed. Anal. 2003, 32, 1149-1158. [CrossRef]

20. Clark, G.L.; Smith, A.F. X-ray diffraction studies of chitin, chitosan, and derivatives. J. Phys. Chem. 1936, 40, 863-879. [CrossRef]

21. Duarte, M.L.; Ferreira, M.C.; Marvão, M.R.; Rocha, J. An optimised method to determine the degree of acetylation of chitin and chitosan by FTIR spectroscopy. Int. J. Biol. Macromol. 2002, 31, 1-8. [CrossRef]

22. Qiao, Y.; Zheng, X. Highly sensitive detection of copper ions by densely grafting fluorescein inside polyethyleneimine core-silica shell nanoparticles. Analyst 2015, 140, 8186-8193. [CrossRef] [PubMed]

(C) 2017 by the authors. Licensee MDPI, Basel, Switzerland. This article is an open access article distributed under the terms and conditions of the Creative Commons Attribution (CC BY) license (http:/ / creativecommons.org/licenses/by/4.0/). 